\title{
The Influence of Phosphorus on the Development of Streptomyces aureofaciens and on its Ability to Produce Chlortetracycline
}

\author{
By A. PROKOFIEVA-BELGOVSKAYA AND LUDMILA POPOVA \\ Antibiotics Research Institute, The Institute of Biophysics of the Academy \\ of Sciences of the U.S.S.R., Moscow, U.S.S.R.
}

SUMMARY: Parallel physiological and cytological investigations of a chlortetracycline-producing culture-Streptomyces aureofaciens, strain 536-indicate some intracellular causes of the dependence of chlortetracycline biosynthesis upon the inorganic phosphorus content of the nutrient medium.

Increase of inorganic phosphorus in the fermentation medium led to a formation of large nuclear elements containing much DNA (in corn steep medium) or ribonucleoproteid complexes in the shape of large volutin granules (corn steep liquor ash medium). As compared with the control, the nuclear substance/cytoplasm ratio in the hyphae is increased. The ability of mycelium overloaded with nuclear elements or volutin granules for chlortetracycline biosynthesis is markedly decreased. The influence of phosphorus on the microscopical structure of mycelium and biosynthesis of antibiotic depends on the composition of medium. The poor quality of certain batches of corn steep liquor used for the production of chlortetracycline is largely due to their high content of inorganic phosphorus.

Within recent years a number of reports have appeared concerning the significance of phosphorus for the production of antibiotics by various microorganisms (Biffi, Boretti, Di Marco \& Penella, 1954; Boretti, Di Marco, Scotti \& Zocchi, 1955; Di Marco, 1956; Shen et al. 1956; Prokofieva-Belgovskaya et al. 1957; Brinberg \& Grabovskaya, 1958). However, the mechanism of its action upon the ability of a strain to synthesize antibiotics remains uncertain. The present investigation deals with the cytological aspect of this problem.

\section{METHODS}

Streptomyces aureofaciens, strain 536, obtained from the Selection Laboratory of this Institute was used in this investigation.

The inoculum was grown on a medium of the following composition: corn steep liquor (50\% solids), 4 g.; starch, 1.5 g.; water $100 \mathrm{ml}$.; pH before sterilization, $6 \cdot 6-6 \cdot 8$.

Two media were used for the fermentation:

Corn steep liquor (50\% solids)

$\mathrm{NH}_{4} \mathrm{NO}_{3}$

$\mathrm{NaCl}$

$\mathrm{CaCO}_{3}$

Starch

Corn steep liquor ash

Water

pH before sterilization
(1)

(2)

Corn steep

Standard medium ash medium

$1 \cdot 0 \mathrm{~g}$.

$0.5 \mathrm{~g}$. $\quad 0.5 \mathrm{~g}$.

$0.2 \mathrm{~g}$. $\quad 0.2 \mathrm{~g}$.

$0.4 \mathrm{~g}$. $\quad 0.4 \mathrm{~g}$.

$2.0 \mathrm{~g}$. $2.0 \mathrm{~g}$.

$0.05 \mathrm{~g}$.

$6 \cdot 6-6 \cdot 8 \quad 6 \cdot 6-6 \cdot 8$ 
The fermentation of $125 \mathrm{ml}$. portions of medium was carried out in $750 \mathrm{ml}$. Erlenmeyer flasks, on a rotary shaker $(200 \mathrm{rev} . / \mathrm{min}$. $)$ at a temperature of 26-28 ${ }^{\circ}$ in the course of $72-80 \mathrm{hr}$. The fermentation medium was inoculated with $2-4 \%(\mathrm{v} / \mathrm{v})$ of the $26-27 \mathrm{hr}$. inoculum culture.

In the course of fermentation the following assays were made: chlortetracycline by the plate method with Bacillus subtilis as a test organism; carbohydrates and phosphorus. The cytological structure of mycelium was also studied.

For cytological analysis a drop of the fermentation broth was placed on a slide, dried and fixed with Carnoy fluid. The morphological structure of the mycelium was studied on preparations stained with methylene blue. The degree of the staining with this dye depends upon the isoelectric point of the protoplasm and serves at the same time as a good index for the RNA content of the protoplasm (Kelley, 1939). For this purpose pyronine may also be used.

To disclose nuclear elements and DNA a Feulgen reaction was used: the mycelium was hydrolysed in $1 \mathrm{~N}-\mathrm{HCl}$ for $7 \mathrm{~min}$. and stained with Schiff's reagent for $3 \mathrm{hr}$.

\section{RESULTS}

For the production of chlortetracycline a medium containing $1.0 \%$ corn steep liquor was used in which phosphorus was present chiefly in the form of phytin and inorganic phosphorus. The total phosphorus contents in the corn steep liquor range from 3 to $5 \%$ of the dry substance. Thus the amount of total phosphorus in the fermentation medium averages $200 \mathrm{mg}$./1. ( 75 mg. free phosphorus/1.). In order to elucidate whether this amount of phosphorus ensures the optimal development of the culture and the biosynthesis of the antibiotic, experiments were performed with the introduction of additional amounts of phosphorus into two media. Phosphorus was introduced just before the inoculation in the form of potassium phosphate.

As the results of these experiments showed the addition of $0.5 \mathrm{~g}$. phosphate/l. led to the same alterations in the fermentation process as those indicated by Di Marco (1956). A much smaller amount of the antibiotic was produced (Fig. 1). The pH value of the medium first fell considerably and then rose markedly. Carbohydrate was consumed more rapidly. More intense growth of the organism was also observed in the experimental flasks in the first hours of fermentation. The autolysis began at an earlier stage of culture development.

To trace phosphorus in the protoplasm of Streptomyces aureofaciens cytological and cytochemical studies of the culture were made in the course of its development on standard medium and on medium enriched with phosphorus.

The cytological changes of the culture during fermentation on corn steep medium are as follows.

During the first period of fermentation (from the inoculation to $20 \mathrm{hr}$. of growth) a mass of mycelia developed in the fermentation broth composed of septate hyphae with homogeneous highly basophilic protoplasm (PI. 1, fig. 1). The loss of basophily of the protoplasm due to the action of ribonuclease and the low isoelectric point of the protoplasm (about $\mathrm{pH} 2 \cdot \mathbf{0}-\mathbf{3 \cdot 0}$; Hagedorn, 
1955a; Prokofieva-Belgovskaya \& Kapitonova, 1959) led to the conclusion that at this period its RNA content was high. This is confirmed by direct biochemical analysis by Biffi et al. (1954), Boretti et al. (1955), Guberniev, Ugoleva \& Torbochkina (1956).

In the process of intensive growth connected with the synthesis of proteins the basophily of the protoplasm gradually decreased. The culture passed into

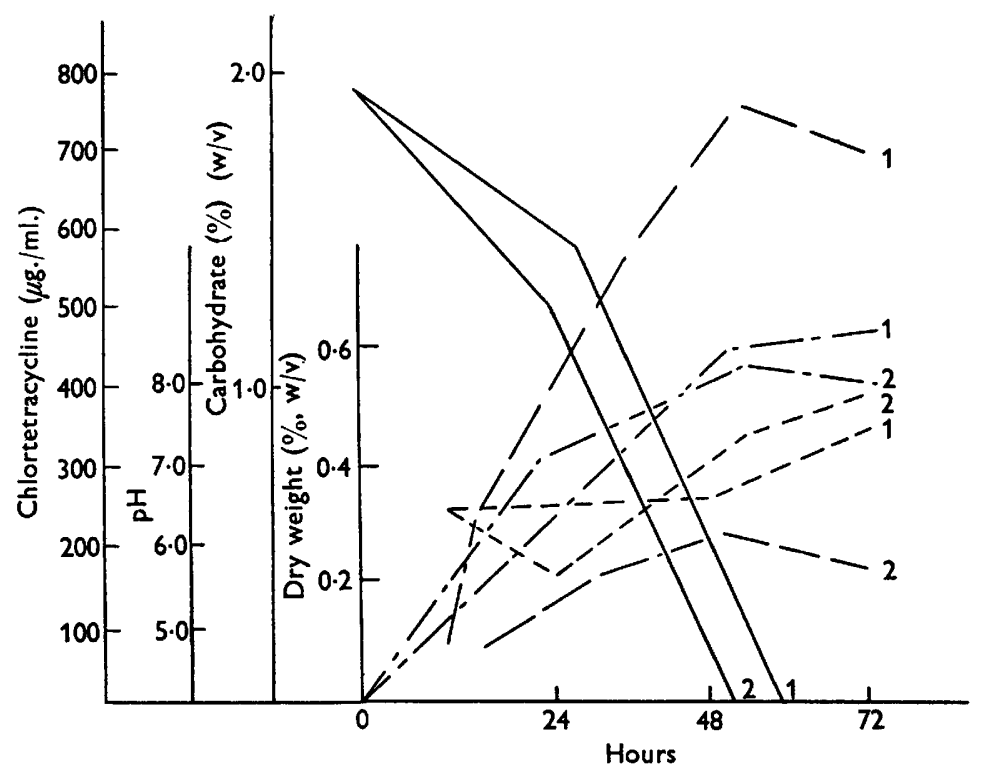

Fig. 1. Influence of inorganic phosphorus on the metabolism of Streptomyces aureofaciens and the chlortetracycline production (corn steep medium). 1, Standard corn steep medium; 2, standard corn steep medium $+0.05 \% \mathrm{KH}_{2} \mathrm{PO}_{4}$. - Carbohydrate;

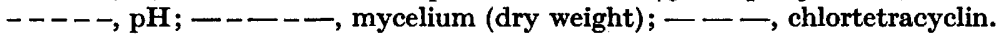

its second stage of development characterized by the slow growth of the mycelial mass, which consisted of thin hyphae, and a low content of RNA in the protoplasm. It was possible at this stage to see numerous small nuclear elements in hyphae (Pl. 1, fig. 2). A fine nuclear reaction points to the presence of DNA in the nuclear substance (Pl. 2, fig. 6). This state of the protoplasm was continued till $72 \mathrm{hr}$. of growth and was characteristic of the period of intensive chlortetracycline production.

In some fermentations after $\mathbf{3 0 - 3 6} \mathrm{hr}$. of growth there developed among the thin hyphae single thickened and fragmented ones, containing intensely basophilic protoplasm and large nuclear elements rich in DNA (Pl. 1, fig. 2). But in highly productive fermentations the number of such hyphae was very small or they were completely lacking. When $0.5 \mathrm{~g}$. phosphate/l. was added to the corn steep medium the development of the culture was markedly altered. After 24-30 hr. of growth a mycelial mass developed, consisting mostly of thickened fragmented, septate or catenulate hyphae with a highly basophilic protoplasm (Pl. 1, fig. 3). The intense staining of the protoplasm with pyronine pointed to a high RNA content. Nuclear staining showed that each fragment of these 
hyphae contained large nuclear elements occupying a considerable part of the fragment's volume (Pl. 2, fig. 6). The intensity of the nuclear reaction led to the conclusion that the DNA content in the nuclear elements was extremely high.

The chief mass of mycelium preserved such a structure till $40-48 \mathrm{hr}$. of growth. From $36 \mathrm{hr}$. more thin secondary hyphae developed in the culture which by that time already contained less nutritive substances, including inorganic phosphorus. By $48 \mathrm{hr}$. the growth of mycelium reached its maximum, the autolysis starting afterwards. Antibiotic content was extremely low.

To determine the ratio of the mass of nuclear elements to that of cytoplasm in the hyphae, the necessary measurements were made on preparations stained after Feulgen. Thin hyphae grown in standard medium (PI. 2, fig. 6) and the enlarged fragmented hyphae which developed in the medium enriched with phosphorus (Pl. 2, figs. 7, 8) were investigated. The diameters of the nuclear elements were assumed to be equal to those of the hyphae. Such assumption does not involve a significant error and was in reasonable agreement with the findings of the present investigation as well as with the photomicrographs of other authors (Hagedorn, 1955 b; Peshkov et al. 1952; Prokofieva-Belgovskaya \& Demianovskaya, 1957; Di Marco, 1956). The cell wall was not stained by the technique used.

Table 1. The ratio of the mass of nuclear elements to that of cytoplasm in the hyphae of mycelium grown on the standard medium, and of mycelium, developed in the medium enriched with phosphates

\begin{tabular}{|c|c|c|c|c|c|c|c|}
\hline & $\begin{array}{c}\text { Total } \\
\text { length of } \\
\text { hyphae } \\
\text { measured } \\
(\mu)\end{array}$ & $\begin{array}{c}\text { No. of } \\
\text { nuclear } \\
\text { elements }\end{array}$ & $\begin{array}{c}\text { Average } \\
\text { diameter } \\
\text { of the } \\
\text { nuclear } \\
\text { elements } \\
(\mu)\end{array}$ & $\begin{array}{c}\text { Range of } \\
\text { variation } \\
(\mu)\end{array}$ & $\begin{array}{c}\text { Total } \\
\text { volume } \\
\text { of } \\
\text { nuclear } \\
\text { elements } \\
\left(\mu^{8}\right)\end{array}$ & $\begin{array}{c}\text { Total } \\
\text { volume } \\
\text { of cyto- } \\
\text { plasm } \\
\left(\mu^{3}\right)\end{array}$ & $\begin{array}{c}\text { Ratio of } \\
\text { volume of } \\
\text { nuclear } \\
\text { elements } \\
\text { to } \\
\text { cytoplasm }\end{array}$ \\
\hline $\begin{array}{l}\text { Corn steep } \\
\text { medium }\end{array}$ & 188 & 114 & 0.29 & $0 \cdot 1-0.4$ & $\mathbf{2 \cdot 2}$ & $11 \cdot 85$ & 0.18 \\
\hline $\begin{array}{c}\text { Corn steep } \\
\text { medium }+ \\
0.05 \% \text { pho }\end{array}$ & 206 & 143 & 0.41 & $0.3-0.6$ & 6.9 & $20 \cdot 80$ & 0.33 \\
\hline
\end{tabular}

Table 1 shows that the mass of cytoplasm in the mycelium enriched with phosphorus was relatively decreased, while that of nuclear elements is increased which leads to a strong shift in the ratio of the fundamental cell components: nucleus/cytoplasm, in favour of the former; its relative quantitative increase is 1.8 times. The content of DNA determined microspectrophotometrically in such nucleoids increased approximately by a factor of 2.5 (Prokofieva-Belgovskaya \& Maslov, to be published).

This type of development became more marked when inorganic phosphorus was introduced into the medium in the presence of antifoam agents. Sunflower oil was used as an antifoam agent. It was introduced into the medium at $0.5 \%(\mathrm{v} / \mathrm{v})$ at inoculation. In the presence of $0.05 \%$ phosphate in this case the 
hyphae of the entire mass of mycelia were highly basophilic up to $40 \mathrm{hr}$. of growth. After $12 \mathrm{hr}$. growth they became fragmented, containing large nuclear elements rich in DNA (Pl. 3, fig. 9). Carbohydrates were rapidly consumed, the medium became more acid and less mycelial mass was accumulated by $\mathbf{7 2} \mathrm{hr}$. of fermentation (Table 2). The mycelium in the experimental flasks was only slightly pigmented, biosynthesis of the antibiotic was almost completely suppressed.

Table 2. The influence of inorganic phosphorus on chlortetracycline synthesis and metabolism of culture in a fermentation medium containing corn steep medium $+0.5 \%(v / v)$ sunflower oil

\begin{tabular}{|c|c|c|c|c|c|c|c|c|c|c|}
\hline \multirow[b]{2}{*}{$\begin{array}{c}\mathrm{KH}_{2} \mathrm{PO}_{4} \\
\text { (g. } / 100 \text { ml.) }\end{array}$} & \multicolumn{2}{|c|}{ Chlortetracycline } & & & pH & & & \multicolumn{2}{|c|}{$\begin{array}{l}\text { Carbohydrate } \\
\text { contents }\end{array}$} & \multirow{2}{*}{$\begin{array}{c}\text { Mycelium } \\
\text { (dry weight), } \\
\text { g. } / 100 \mathrm{ml} ., \\
72 \mathrm{hr} .\end{array}$} \\
\hline & mg./l. & $\begin{array}{c}\text { Inhib. } \\
(\%)\end{array}$ & Initial & $6 \mathrm{hr}$. & $24 \mathrm{hr}$. & $48 \mathrm{hr}$. & $72 \mathrm{hr}$. & $24 \mathrm{hr}$. & $48 \mathrm{hr}$. & \\
\hline 0.05 & 26 & $97 \cdot 6$ & $6 \cdot 6$ & 6.5 & $6 \cdot 0$ & $6 \cdot 6$ & $7 \cdot 8$ & 1.35 & $0 \cdot 15$ & $0 \cdot 74$ \\
\hline Control & 1076 & - & $6 \cdot 6$ & $6 \cdot 6$ & $6 \cdot 6$ & $6 \cdot 4$ & $6 \cdot 8$ & $1 \cdot 76$ & 0.75 & 0.98 \\
\hline
\end{tabular}

Table 3. The influence of various concentrations of inorganic phosphorus on the production of chlortetracycline

\begin{tabular}{|c|c|c|c|c|}
\hline \multirow[b]{2}{*}{$\begin{array}{c}\mathrm{KH}_{2} \mathrm{PO}_{4} \\
\text { (g./100 ml. })\end{array}$} & \multicolumn{2}{|c|}{$\begin{array}{l}\text { Corn steep medium. } \\
\text { Chlortetracycline }\end{array}$} & \multicolumn{2}{|c|}{$\begin{array}{c}\text { Corn steep medium }+ \\
0.5 \% \text { sunflower oil. } \\
\text { Chlortetracycline }\end{array}$} \\
\hline & mg./l. & $\begin{array}{c}\text { Inhib. } \\
(\%)\end{array}$ & mg./l. & $\begin{array}{c}\text { Inhib. } \\
(\%)\end{array}$ \\
\hline 0.01 & 856 & 13 & 619 & 24 \\
\hline 0.02 & 739 & 25 & 326 & 60 \\
\hline 0.03 & 512 & 48 & 212 & 74 \\
\hline 0.04 & - & 一 & 122 & 85 \\
\hline Control & 985 & - & 814 & - \\
\hline
\end{tabular}

Further investigations showed that even the introduction of trifling quantities of potassium phosphate into the medium ( $0 \cdot 1 \mathrm{~g}$. $/ 1$.) decreased the chlortetracycline biosynthesis by $13 \%$ when fermentation took place in corn steep medium and by $24 \%$ in corn steep medium with antifoam agent (Table 3 ).

Both the total and the inorganic phosphorus content changed in the course of the fermentation. Phosphorus was taken up by the organism chiefly during the first day of growth. When grown in the presence of large amounts of phosphorus mycelium contains more phosphorus than on ordinary medium (Fig. 2).

Studies were carried out on the comparison of the corn steep liquors containing different amounts of inorganic phosphorus (Table 4).

In two of the corn steep liquors tested (25 and K-78), inorganic phosphorus was present in much larger quantities than in the rest. Experiments show that the smallest amount of antibiotic was produced on medium containing corn steep liquor with a comparatively large amount of inorganic phosphorus (25 and K-78). The utilization of corn steep liquors containing more than $0.9 \%$ inorganic phosphorus in the fermentation medium led, as a rule, to the same 
Table 4. The influence of different batches of corn steep liquor on biosynthesis of chlortetracycline

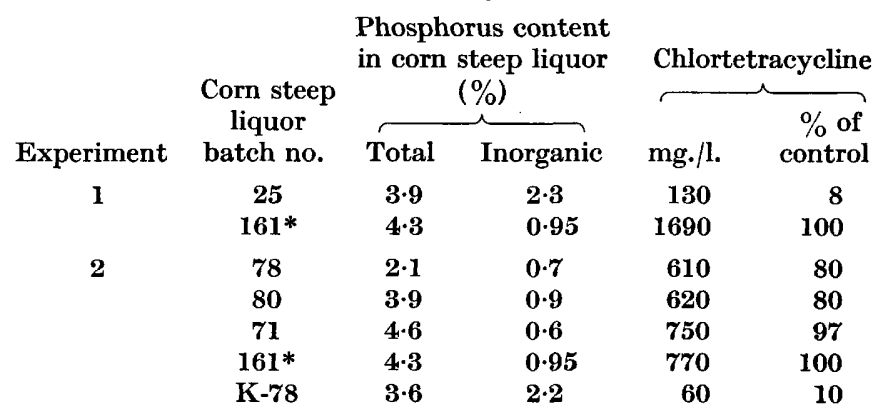

* No. 161 is the control in this experiment, for it was used in all preceding experiments.

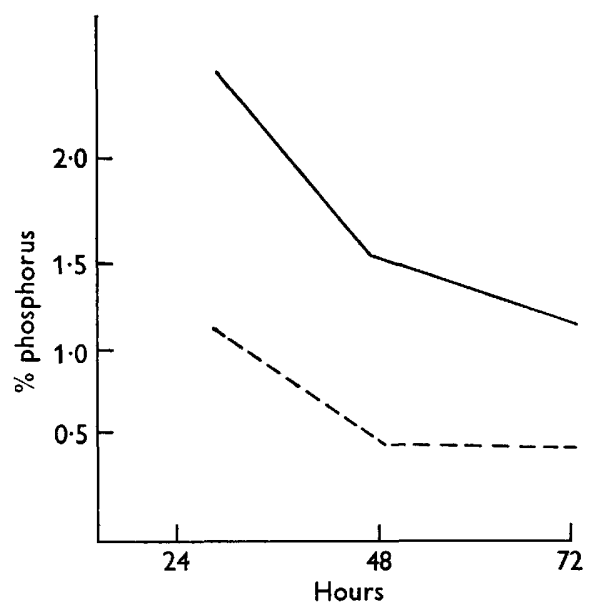

Fig. 2. Contents of phosphorus in mycelium grown in: standard corn steep medium, - . . - ; standard corn steep medium $+0.05 \% \mathrm{KH}_{2} \mathrm{PO}_{4}$, -

changes in the structure and development of the mycelium as those that occurred on medium to which $0.05 \%$ phosphates were added (Pl. 3, figs. 10, 11). Markedly basophilic septate hyphae with large nuclear elements containing a considerable amount of DNA developed in the culture (Pl. 2, fig. 8). Chlortetracycline production by such mycelia is extremely weak (60-150 mg./l.).

The mycelium which developed in a medium containing corn steep liquor ash differed at all stages of growth from that found in standard medium by its thinner hyphae, smaller amount of RNA in the protoplasm and smaller nuclear elements with a less distinct nuclear reaction (Pl. 1, fig. 4).

When this medium was enriched with phosphates $(0.1-0.5 \mathrm{~g} . / 1$.$) the actino-$ mycete reacted in a different way than on standard medium. Addition of only $0 \cdot 1 \mathrm{~g}$. phosphate/l. sufficed to induce after $36 \mathrm{hr}$. of growth the appearance in the weakly basophilic protoplasm of volutin granules, which after $48 \mathrm{hr}$. form large blocks in the protoplasm (Pl. 1, fig. 5). Chlortetracycline synthesis was also markedly decreased (Table 5). 
Table 5. The influence of inorganic phosphorus on the biosynthesis of chlortetracycline on corn steep liquor ash medium

\begin{tabular}{ccc}
$\mathrm{KH}_{2} \mathrm{PO}_{4}$ & \multicolumn{2}{c}{ Chlortetracyclin } \\
\cline { 2 - 3 }$(\mathrm{g} . / 100 \mathrm{ml})$. & $\mathrm{mg} / \mathrm{l}$. & Inhib. (\%) \\
0.01 & 180 & 56 \\
0.02 & 30 & 93 \\
0.05 & 0 & 100 \\
Control & 410 & -
\end{tabular}

\section{DISCUSSION}

Biochemical data show (Demyanovskaya \& Belozersky, 1954) that 72-76 \% of actinomycete mycelium consists of nucleoproteins. The nucleic acid content of these varies from 11 to $17 \%$.

The ability of Streptomyces aureofaciens to produce chlortetracycline is closely connected with a definite state of the protoplasm characteristic for the second phase of its development. One of the major indices of this is the state of the nucleoproteins in the cytoplasm and the nuclear elements (Scotti \& Zocchi, 1955; Prokofieva-Belgovskaya, Pestereva \& Rudaya, 1956; Prokofieva-Belgovskaya \& Orlova, 1956). A comparison of the physiological, cytochemical and biochemical data (Carvajal, 1947; Bringmann, 1951; Peshkov et al. 1952; Prokofieva-Belgovskaya et al. 1956; Prokofieva-Belgovskaya \& Demianovskaya, 1957) led to the conclusion that the major intracellular factor which determines the changes in metabolism and the transition from the first phase of development (intensive growth) to the second phase (retarded growth and intensive production of the antibiotic) is the decrease in the RNA content of the protoplasm. The maximum amount of RNA in the protoplasm (according to cytochemical data and biochemical analysis) is observed during the period of 10-12 hr. growth, or 20-30 hr. before the maximum accumulation of mycelium. Hence, the actinomycete cell at first accumulates a maximum amount of nucleic acid and then utilizes it during its later growth. These findings correspond to those obtained with other organisms (Vendrely, Tulasne \& Minck, 1948).

A number of investigations (Boretti et al. 1955; Biffi et al. 1954; Di Marco, 1956; Shen et al. 1956; Brinberg \& Grabovskaya, 1958; Popova, to be published), like the present work, have established that the rise in the inorganic phosphorus contents of the fermentation medium leads to an increase in the amount of phosphorus-containing compounds in the mycelium. The physiological properties of such mycelia are markedly altered: the growth of the culture is accelerated, so is its consumption of carbohydrates, the synthesis of the phosphorus-containing components of the protoplasm-RNA and DNA-is increased, thicker hyphae develop which remain basophilic for a long time; the ability these hyphae have for the biosynthesis of the antibiotic is decreased.

A number of investigators (Shen et al. 1956; Di Marco, 1956) connect the inhibition of chlortetracycline synthesis under these conditions with the change in carbohydrate metabolism. 
The development of Streptomyces aureofaciens culture may proceed in two different directions depending upon the inorganic phosphorus contents of the corn steep medium. Each of these is characterized by cytological peculiarities of the growth of the culture and its development, physiological properties and its ability to synthesize antibiotic. These different lines of development are determined by the relation between the structural elements of the cell: the cytoplasm and the nuclear elements.

Type I. The accumulation of nuclear substance in the hyphae is relatively low, its DNA content is small (a faint nuclear reaction), the growth of mycelium is connected chiefly with the accumulation of cytoplasm in the thin hyphae, the RNA content of which drops progressively. The ability for synthesis of the antibiotic is high (standard corn steep medium).

Type II. Nuclear substance accumulates intensively in the protoplasm in the form of large nuclear elements rich in DNA. The increase in nuclear substance by means of the reproduction of nuclear elements and their increase in size is accompanied by the inhibition of the growth of the cytoplasmic body of the cell. The thick hyphae are fragmented and show a tendency towards cellformation. The ability for synthesizing antibiotic is markedly decreased (on corn steep medium enriched with inorganic phosphorus).

A comparison of our data with those of Di Marco (1956) and Shen et al. (1956) shows that there probably exists a strong interdependence between the synthesis of nucleic acids, the pathways of carbohydrate metabolism, and the capacity of Streptomyces aureofaciens culture to synthesize chlortetracycline. This conclusion is supported by the fact that when the conditions of aeration become worse and modify the pathways of the carbohydrate metabolism in accordance with the Embden-Meyerhof scheme, the microscopical structure and physiological properties of mycelium change. This change is similar to those observed after the enrichment of the medium with phosphorus (Dr Zolotnitsky, unpublished).

Of great importance also is the fact that fermentation of cultures producing streptomycin, terramycin and nistatin on media enriched with phosphorus leads to changes in their microscopical structure and physiological properties which are similar to the changes occurring in Streptomyces aureofaciens (Prokofieva-Belgovskaya et al. 1957).

Cytological studies of multicellular organisms have long ago established the general fact that when the nucleus passes into the mitotic state conditioned by the reduplication of chromosomes and the increase in their DNA contents, the cell comes out of its 'metabolic' or 'working' state (Berill \& Huskins, 1936; Peter, 1940; Zalkind, 1952; and others); its specific functions are now completely inhibited (starch formation, the formation of glycogen, etc.). It is probable that in a medium containing a large amount of phosphorus the actinomycete cell behaves in the same way. Its metabolism under these conditions proceeds in the direction of the synthesis of nucleic acids (RNA and DNA) and the reduplication of nuclear elements, but not in the direction of the specific antibiotic synthesis connected with the growth of the cytoplasmic body of the cell. 
It is possible that the increase of the size of nucleoids and of their DNA content is determined by the reproduction of the elementary nuclear structures of which the nucleoid is composed, this process being analogous to the polytenization of chromosomes in plants and animals.

The enrichment of actinomycete protoplasm with phosphorus in a medium with corn steep liquor ash stimulates not the reproduction of large nuclear elements with a high DNA content, but the synthesis and accumulation in the protoplasm of complex combinations of RNA and metaphosphates. Such are, evidently, the volutin granules described by Belozersky (1945) and Wiame (1945). This disturbance of nucleic acid metabolism in the protoplasm also leads to the decrease in capacity to synthesize chlortetracycline.

The data showing that the rise in inorganic phosphorus in the medium influences first of all the nucleic acid metabolism agree well with the fact that the chief mass of phosphorus in the medium is used by the organism during the first days of its growth, i.e. when the RNA synthesis is at its highest (Brinberg \& Grabovskaya, 1958).

The action of inorganic phosphorus differs from that of its organic compounds (L. Popova, to be published). The introduction of phytin into the medium did not exert any noticeable effect on the cytology of the culture and its development or on its physiological properties, including the ability for the biosynthesis of the antibiotic.

The experiments with batches of corn steep liquor lead one to believe that the difference in productivity of separate batches of corn steep liquor depends upon difference in their inorganic phosphorus content. Batches of corn steep liquor with a large amount of inorganic phosphorus stimulate the development of mycelium overloaded with nuclear elements with high contents of DNA and possessing a low ability for chlortetracycline synthesis.

\section{REFERENCES}

Belozersky, A. N. (1945). On the chemical nature of volutin. Microbiology, Moscore, $14,1,29$.

Berill, N. \& Huskins, C. (1936). The 'resting' nucleus. Amer. Nat. 70, 257.

Biffi, G., Boretti, G., Di Marco, A. \& Penella, P. (1954). Metabolic behaviour and chlortetracyclin production by Streptomyces aureofaciens in liquid culture. Appl. Microbiol. 2, 288.

Boretti, G., Di Marco, A., Scotti, T. \& Zocchi, P. (1955). Variazioni morphologiche e biochimiche dello Streptomyces aureofaciens in relazione alla produzione di chlorotetracyclina. G. Microbiol. 1, 97.

Bringerg, S. L. \& Grabovskaya, O. B. (1958). The significance of phosphorus for the biosynthesis of streptomycin. Microbiology, Moscow, 27, 407.

BringmanN, G. (1951). Elektromikroskopische und Lichtmikroskopische Studien zur Morphologie und Entwicklung von Streptomyces griseus Krainsky. Z Zbl. Bakt. 157, 349.

Carvajal, F. (1947). The production of spores in submerged cultures by some Streptomyces. Mycologia, 39, 425.

Demianovskaya, N. S. \& Belozersky, A. N. (1954). Desoxyribonucleic acid of Actinomyces globisporus streptomycini Kras. in the process of its development. Biochem. Leningrad, 19, 688. 
Guberniev, M. A., Ugoleva, N. A. \& Torbochkina, L. M. (1956). Nucleic acids and phosphorus compounds in the mycelium of Actinomyces aureofaciens at different stages of development. Antibiotiki, Moscow, 3, 8.

Hagedorn, H. (1955 a). Untersuchungen über den isoelektrischen Punkt bei Actinomyceten. Protoplasma, 45, no. 1, 115.

Hagedorn, H. (1955 b). Beiträge zur Cytologie und Morphologie der Actinomyceten. Z. Bakt. (II. Abt.), 108, 353.

Kelley, E. (1939). Reactions of dyes with cell substances. J. biol. Chem. 127, 55.

Marco, A. Di (1956). Metabolism of Streptomyces aureofaciens and biosynthesis of chlortetracyclin. G. microbiol. 2, 285.

Peshrov, M. A., Rautenstein, J. I., Sorokina, M. M., Cherednichenko, A. F. \& Sharkova, A. S. (1952). Cytological changes of the Actinomyces globisporus streptomycini mycelium under the influence of actinophage. Microbiology, Moscow, 21, 665.

Peter, K. (1940). Die indirekte Teilung der Zelle in ihren Beziehungen zu Tätigkeit, Differenzierung und Wachstum. Z. Zellforsch. 30, 721.

Prokofieva-Belgovskaya, A. A. \& Demianovskaya, N. S. (1957). Cytological and biochemical changes in Actinomyces globisporus streptomycini Kras. in the process of antibiotic production in submerged culture. Microbiology, Moscoze, 26, 22.

Prokofieva-Belgovskaya, A. A. \& Kapitonova, O. N. (1959). Isoelectric point of cytoplasm and nuclear elements of Actinomyces streptomycini Kras. Bull. Acad. Sci., U.S.S.R. (in the Press).

Prokofieva-Belgovskaya, A. A. \& Orlova, N. V. (1956). The peculiarities of growth and development of actinomycetes producing streptomycin, biomycin, and terramycin in submerged cultures. Bull. Acad. Sci., U.S.S.R. 5, 59.

Prokofieva-Belgovskaya, A. A., Pestereva, G. D. \& Rudaya, S. M. (1956). Peculiarities of growth and development of Actinomyces rimosus under the conditions of bottom fermentation. Microbiology, Moscow, 25, 668.

Prokofieva-Belgovskaya, A. A., Popova, L. A., Orlova, N. V., Severin, V. A., Gorskaya, S. V. \& Kapitonova, O. N. (1957). Dependence of the antibiotic activity of actinomycetes on the peculiarities of their growth and development. Abstracts of reports presented at the Second All-Union Conference on Antibiotics (Russian), 52.

ScotTi, T. \& Zocchi, P. (1955). Studio della struttura del micelio di Streptomyces aureofaciens. G. microbiol. $1,35$.

Shen, S. C., Soohg, H. Y., Chen, J. P., Hung, M. M. \& Yin, H. C. (1956). III. The effect of phosphate on the utilization of carbohydrates by Streptomyces aureofaciens and the production of aureomycin. Acta Exp. Biol. Sinica, 5, 2.

Vendrely, R., Tulasne, R. \& Minck, R. (1948). Premières observations sur les modifications chimiques qu'apporte la penicilline chez le Staphylocoque. C.R. Soc. Biol., Paris, 142, 239.

Wiame, J. (1954). Presence of a polyphosphoric acid nucleic derivative in yeast. C.R. Soc. Biol., Paris, 140, 897.

ZaLkind, S. J. (1952). Mitosis and the functional activity of the cell. Advanc. Modern Biol. 33, 431 (Russian). 


\section{EXPLANATION OF PLATES}

The mycelium of Streptomyces aureofaciens were fixed with Carnoy fluid and stained with methylene blue $(1: 1000)$ or after Feulgen. Photomicrographs were made with a Zeiss microscope, ob. 90, N.A. 1·3, ocular $\times 15$.

Plate 1

magnification $\times \mathbf{2 5 0 0}$.

Fig. 1. Mycelium after $18 \mathrm{hr}$. growth on a standard corn steep medium. Hyphae with a homogeneous basophilic protoplasm. Methylene blue.

Fig. 2. Mycelium after $40 \mathrm{hr}$. growth on a standard corn steep medium. Decrease of the protoplasm basophily and the differentiation in it of fine nuclear elements. Methylene blue.

Fig. 3. Mycelium after $40 \mathrm{hr}$. growth on a corn steep medium $+0.05 \%$ phosphates. Hyphae are fragmented, the protoplasm highly basophilic. Methylene blue.

Fig. 4. Mycelium after $48 \mathrm{hr}$. growth on a corn steep ash medium. Methylene blue.

Fig. 5. Mycelium after $48 \mathrm{hr}$. growth on a corn steep ash medium $+0.01 \%$ phosphates. The protoplasm contains large volutin granules. Methylene blue.

\section{Plate 2}

magnification $\times 1964$.

Fig. 6. Mycelium after $40 \mathrm{hr}$. growth on a standard corn steep medium. A weak nuclear reaction of the nuclear elements. Feulgen.

Fig. 7. The nuclear reaction of mycelium after $40 \mathrm{hr}$. growth on a corn steep medium $+0.05 \%$ phosphates. The fragmented protoplasm contains large nuclear elements with high content of DNA. Feulgen.

Fig. 8. Mycelium after $40 \mathrm{hr}$. growth on a standard medium with the corn steep liquor no. 25 . A pronounced nucleal reaction of large nuclear elements. Feulgen.

Fig. 9. Mycelium after $36 \mathrm{hr}$. growth on a corn steep medium $+0.05 \%$ phosphates in the presence of antifoam agent. Methylene blue.

Fig. 10. Mycelium after $40 \mathrm{hr}$. growth on a standard medium with a corn steep liquor no. 161 (0.95\% of inorganic phosphorus). Methylene blue.

Fig. 11. Mycelium after $40 \mathrm{hr}$. growth on a standard medium with corn steep liquor no. 25 (2.2\% of inorganic phosphorus). Methylene blue.

(Received 7 August 1958) 
Journal of General Microbiology, Vol. 20, No. 3
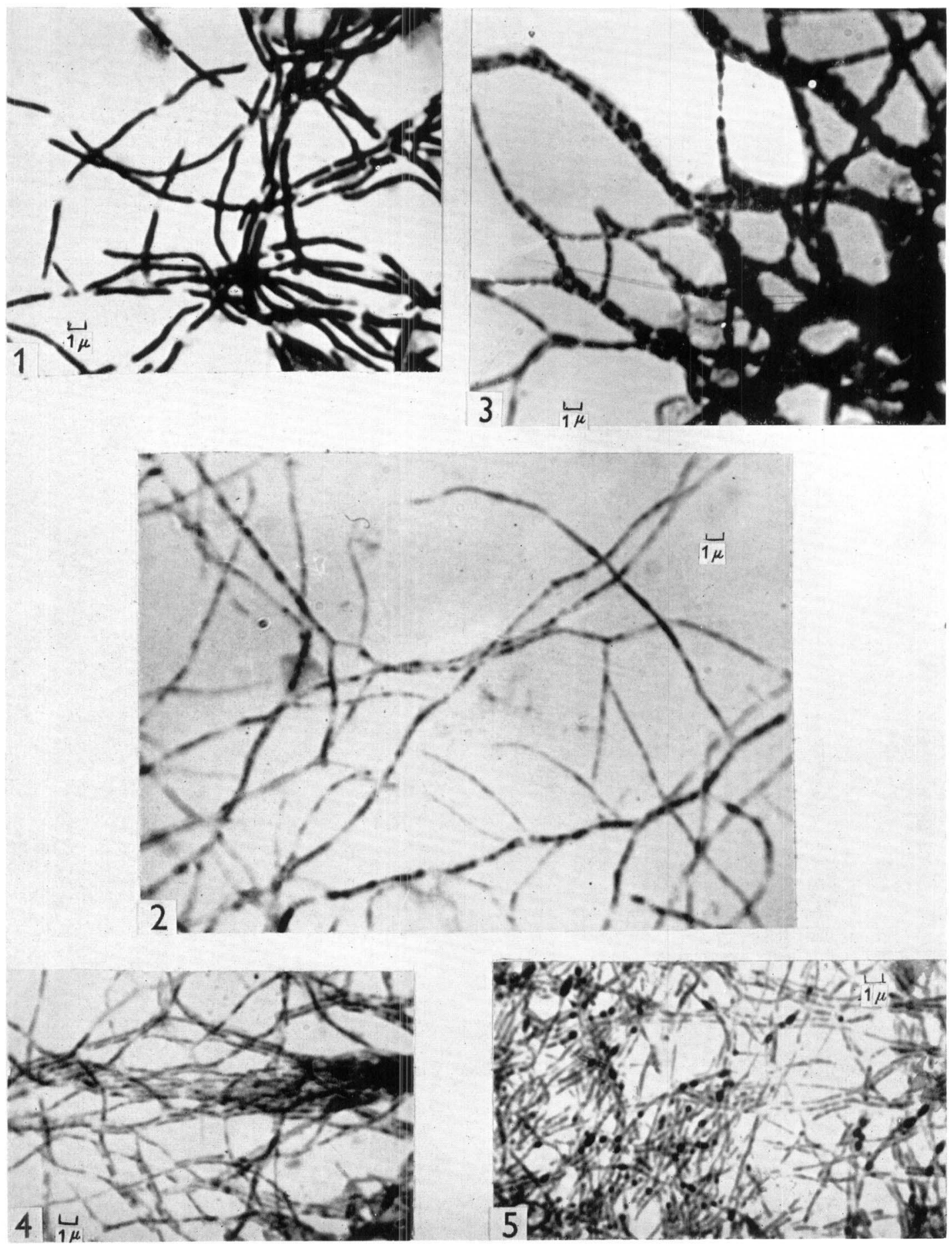

A. Prokofieva-Belgovskaya \& L. Popova-Chlortetracycline production By S. aureofaciens. Plate 1 
Journal of General Microbiology, Vol. 20, No. 3
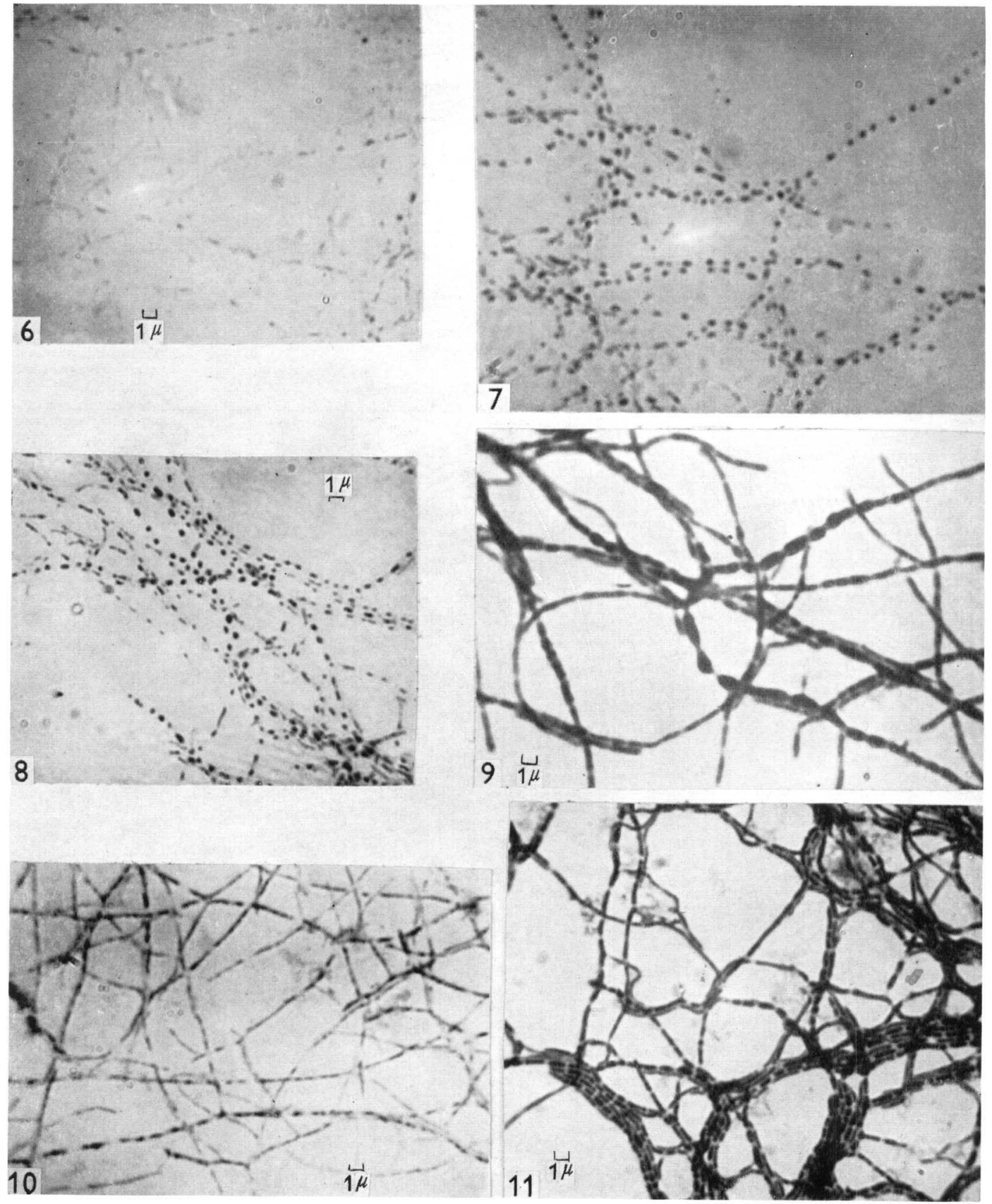

A. Prokofieva-Belgovshaya \& L. Popova-Cinlortetracychine production By S. aUreofaciens, Plate 2 